\title{
Test Study on Road Performance of Soils Stabilized by Liquid Stabilizer
}

\section{in Seasonally Frozen Regions}

\author{
CHEN Yao ${ }^{1,2, a}$, TAN Yi-qiu, \\ ${ }^{1}$ School of Transportation Science and Engineering, Harbin Institute of Technology, Harbin, China \\ ${ }^{2}$ College of Architectural and Civil Engineering,Heilongjiang University, Harbin, China \\ achenyao170105@126.com, ${ }^{\mathrm{b}}$ yiqiutan@163.com
}

Key words: stabilizer,soil, base course,performance,seasonally frozen region

\begin{abstract}
In seasonally frozen regions, road construction often suffers from low strength,lack of durability, etc. Improving the typical clay's workability in Changchun with lime and the Base-Seal stabilizer (BS-100) shows promising results. A comprehensive investigation to assess the soil characteristics influence is undertaken, so as the lime and liquid stabilizer (BS-100) content on the physical properties of stabilized soils in seasonally frozen regions. The optimum mix proportions, unconfined compressive strength, splitting strength, modulus of resilience, freeze-thaw action, water resistance and penetration-resistance were outlined. By comparing with current specifications, the Base-Seal stabilized soil as base material has higher early strength, higher after-strength and better frost stability.The results can be applied in road construction in seasonally frozen regions.
\end{abstract}

\section{Introduction}

Adequate road network is an important factor to the socio-economic development in a country. However, the quantum of materials required for the construction is usually huge. Conventional materials such as cement, aggregates, steel are lacking and quite expensive ${ }^{[1]}$. As we all know, soil is the cheapest available material utilized by man for various construction-related purposes. Stabilization of soils with low-bearing capacity is an economical way for road construction. It can be used to form subase, road base and surface courses, a great deal of granular materials and cementious materials can be saved. So the solid wastes pollution and the consumption of natural resources will be reduced ${ }^{[2-5]}$.

The natural durability and strength of the soil can be improved through the process of "soil stabilization' using different types of stabilizers. The main methods ${ }^{[6-7]}$ by which soils are stabilized for road purposes are:(1) mechanical or granular stabilization;(2) cement stabilization;(3) lime and lime-pozzolan stabilization ${ }^{[8]}$; (4) bituminous stabilization; and (5)stabilizer reinforced soil. In recent years, the use of cementitious material like Portland cement, hydraulic lime and lime-pozzolana mixes as stabilizer is quite common. But for these stabilized soils, their early strength is usually very low, and they have inadequate frost stability and water resistance $^{[9]}$.Therefore, a new type of lime-liquid stabilizer material is used as road base material in order to improve the typical clay's workability in seasonally frozen regions. The following sections present the experimental process and the results of various tests conducted on stabilized soils. 


\section{Experimental Process}

\subsection{Materials}

Liquid stabilizer-'BS-100', it contains no acids or explosive materials and is environmentally safe, non-toxic, non-corrosive, non-flammable,non-allergenic.

Slake-lime-It is in line with the technical requirements for the III grade with $55.3 \%$ reactive $\mathrm{CaO}+\mathrm{MgO}$.

Cement $-\mathrm{C} 32.5$ ordinary Portland cement.

Soil—The engineering properties of the original soil are presented in Table[1].

Table1 The engineering properties of the soil

\begin{tabular}{cccccc}
\hline$\omega_{l}(\%)$ & $\omega_{p}(\%)$ & $I_{P}$ & $\rho_{d \max }\left(\mathrm{g} / \mathrm{cm}^{3}\right)$ & $\omega_{o p}(\%)$ & Soil classification \\
\hline 38.1 & 23.0 & 15.1 & 1.92 & 12 & MLS \\
\hline
\end{tabular}

\subsection{Experimental design}

Attempt to determine the optimum mix proportions, comprehensive series of laboratory tests were conducted with various percentage and combination of stabilizers. It consisted of standard proctor compaction and 7-day unconfined compression strength. The relative compaction of the test sample is $98 \%$. The specimens were stored in curing room $\left(20 \pm 2{ }^{\circ} \mathrm{C}, 95 \pm 2 \% \mathrm{RH}\right)$. Table[2] presents a summary of stabilized soil mixtures with various stabilizer combinations.

Table2 Stabilizer combination scheme for stabilized soils

\begin{tabular}{ccccccc}
\hline Combination & Lime (\%) & Cement $(\%)$ & BS-100(\%) & $\boldsymbol{\rho}_{\text {dmax }}\left(\mathbf{g} / \mathbf{c m}^{\mathbf{3}}\right)$ & $\boldsymbol{\omega}_{\boldsymbol{o p}} \mathbf{( \% )}$ & $\mathbf{7 - U C S}(\mathbf{M p a})$ \\
\hline 1 & 3 & 0 & 0.25 & 1.85 & 12.5 & 0.93 \\
2 & 3 & 0 & 0.28 & 1.85 & 12.5 & 1.03 \\
3 & 3 & 0 & 0.32 & 1.85 & 12.5 & 1.06 \\
4 & 5 & 0 & 0.25 & 1.84 & 12.8 & 1.62 \\
5 & 5 & 0 & 0.28 & 1.84 & 12.8 & 1.79 \\
6 & 5 & 0 & 0.32 & 1.84 & 12.8 & 1.69 \\
7 & 7 & 0 & 0.25 & 1.83 & 13.0 & 1.78 \\
8 & 7 & 0 & 0.28 & 1.83 & 13.0 & 1.67 \\
9 & 7 & 0 & 0.32 & 1.83 & 13.0 & 1.60 \\
10 & 0 & 2 & 0.28 & 1.92 & 12.1 & 0.74 \\
11 & 0 & 2 & 0.32 & 1.92 & 12.1 & 0.60 \\
12 & 0 & 4 & 0.28 & 1.91 & 12.3 & 1.33 \\
13 & 0 & 4 & 0.32 & 1.91 & 12.3 & 1.40 \\
14 & 0 & 6 & 0.28 & 1.90 & 12.6 & 1.66 \\
15 & 0 & 6 & 0.32 & 1.90 & 12.6 & 1.68 \\
\hline
\end{tabular}

1)The unconfined compressive and splitting strengths were determined on a hydraulic testing machine under strain-control at a loading speed of $1 \mathrm{~mm} / \mathrm{min}$ after curing for 28, 90,180 days.

2)The modulus of resilience was tested at 7,28 days. The specimens were soaked in the water with room temperature for $24 \mathrm{~h}$ before the test.

3)Durability tests were conducted by studying the effect of water immersion on the unconfined compressive strength, freezing and thawing cycles on the strength and penetration-resistance.

Cylindrical specimens were examined for the effect of water immersion. The specimens were cured for 6 days, wrapped in plastic sheets in the curing room and then unwrapped from plastic sheets to put into water containers stored in the curing room until testing for soaked compressive strength $(S s)$ at 1,3 and 7 days ${ }^{[10]}$. 
The freezing and thawing tests were performed by a programmable freezing apparatus. The stabilized soil specimens were subjected to freezing and thawing tests in accordance with JTG D50-2006-A.2 and other testing methods ${ }^{[11]}$.All specimens were cured for 27 days and soaked in the water with room temperature for $24 \mathrm{~h}$ before the freezing and thawing cycles, and then placed in the freezing apparatus and conditioned at $-35^{\circ} \mathrm{C}$ for $24 \mathrm{~h}$. Then the specimens were transferred from the freezing apparatus into a test room at $20 \pm 2{ }^{\circ} \mathrm{C}, 95 \pm 2 \% \mathrm{RH}$ for $24 \mathrm{~h}$. This freezing and thawing cycle was repeated 5 times and then these specimens were subjected to the unconfined compressive strength tests.

4)The falling-head permeability tests were conducted at 7 and 28 days. The specimens were placed inside a cylindrical mold and then allowed to flow through the specimens. The test apparatus consists of a mold with lids and a standpipe $10 \mathrm{~mm}$ in diameter and $130 \mathrm{~mm}$ in length.

\section{Results and Discussion}

\subsection{Standard proctor compaction tests}

This test was used to determine the effect of stabilizers without BS-100 on maximum dry density and optimum moisture content. A summary of the results for the compaction tests on stabilized soils with various percentages of lime or cement is shown in Table[2]. We can see that the maximum dry density decreases and the optimum moisture content increases as lime content increases from 3\% to $7 \%$. The addition of lime raises the optimum moisture content. This is because the pozzolanic reaction of lime with the soil constituents tends to increase the optimum moisture content.

Similar behaviour was also observed in the case of cement stabilized soils when cement content is increased from 2 to $6 \%$. But comparing with the lime, the increase in optimum moisture content with the addition of cement is attributed to the extra water required for cement hydration.

\subsection{The optimum mix proportion}

According to Table[2], lime stabilized soils have a higher unconfined compressive value after 7-day curing. This indicates that the combination of stabilizer and lime has a better stabilizing effect on the clayey soils in Changchun.

Table[2] also shows that when stabilizer dosage increases from $0.25 \%$ to $0.32 \%$ with $3 \%$ lime proportion, the 7-day unconfined compressive strength increases from0.93 $\mathrm{MPa}$ to $1.06 \mathrm{MPa}$. Although the strength keeps increasing, the increasing rate is far less than that when stabilizer dosage is relatively higher. When stabilizer dosage increases from $0.25 \%$ to $0.32 \%$ with $5 \%$ lime proportion, the curve of strength vs.mix formulation is a parabolic one. The strength curve has a declining tendency when stabilizer dosage increases from $0.25 \%$ to $0.32 \%$ with $7 \%$ lime proportion.

According to the above analysis, it can be noted: (1) a blind increase in mix proportion of stabilizer and lime cannot bring a strength increase. Instead, that makes the construction cost much higher; (2) with the mix proportion of $5 \%$ lime and $0.28 \%$ stabilizer, the peak value of the 7 -day unconfined compressive strength (1.79MPa) can be achieved. A comparably higher value of 7-day strength $(1.62 \mathrm{MPa})$ can also be obtained with $5 \%$ lime and $0.25 \%$ stabilizer.

Based on the above results and contrasts between the 7-day unconfined strength value and the required value in the Specification in China, it is decided that the optimum mix proportion is $5 \%$ lime and $0.25 \%$ stabilizer.

Table 3 The data of unconfined compressive strength

\begin{tabular}{cccccc}
\hline \multicolumn{2}{l}{ The optimum mix proportion(\%) } & \multicolumn{4}{c}{ unconfined compressive strength(MPa) } \\
\hline lime & BS-100 & $7 \mathrm{~d}$ & $28 \mathrm{~d}$ & $90 \mathrm{~d}$ & $180 \mathrm{~d}$ \\
5 & 0.25 & 1.55 & 2.24 & 3.04 & 3.92 \\
\hline
\end{tabular}

2.3 The unconfined compressive strength

As shown in Table[3], the 7-day moisture-laden unconfined compressive strength of BS-100 stabilized soils is $1.55 \mathrm{MPa}$. According to the Specification of Asphalt Pavement Design for Highway of the Ministry of Communications of China, the 7-day strength of the lime fly ash road base material should be more than or equal to $0.8 \mathrm{MPa}$. However, the 7 -day strength value we get increases by $0.75 \mathrm{MPa}$, higher than the required value. 
The unconfined compressive strength of stabilized soils is increasing with the increase in age, and keeps a relatively higher increasing rate. The 28 -day strength is $2.24 \mathrm{MPa}$, which increases by $44.5 \%$ compared to the 7-day strength; the 90 -day strength is $3.04 \mathrm{Mpa}$, which increases by $35.71 \%$, compared to the 28 -day strength; the 180 -day strength of stabilized soils is $3.92 \mathrm{Mpa}, 28.9 \%$ higher than the 90-day strength.Fig.1 presents the increasing tendency curve of the unconfined compressive strength of Base-Seal stabilized soils.

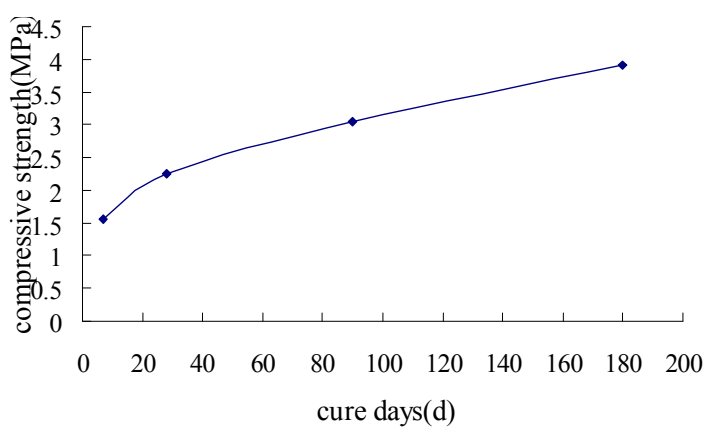

Fig1 The data of unconfined compressive strength

Table4 The data of splitting strength

\begin{tabular}{ccccc}
\hline \multicolumn{2}{c}{ mix proportion(\%) } & \multicolumn{3}{c}{ splitting strength(MPa) } \\
\hline lime & BS-100 & $28 \mathrm{~d}$ & $90 \mathrm{~d}$ & $180 \mathrm{~d}$ \\
5 & 0.25 & 0.26 & 0.38 & 0.45 \\
\hline
\end{tabular}

\subsection{The splitting strength}

It is noted in Table[4] that the splitting strength of BS-100 stabilized soils is comparably higher in the early period. At the age of 28 days, the splitting strength is $0.26 \mathrm{MPa}$. It keeps increasing with the increase in age. The 90 -day splitting strength is $0.38 \mathrm{MPa}, 46.2 \%$ higher than that of the 28 -day stabilized soils; the 180 -day splitting strength is $0.45 \mathrm{MPa}, 18.4 \%$ higher than that of the 90 -day stabilized soils.Fig. 2 is the increasing tendency curve for the splitting strength of BS-100 stabilized soils vs. age.

\subsection{The resilience modulus}

It is shown in Table[5] that the resilience modulus of BS-100 stabilized soils is $262 \mathrm{MPa}$ when the age is 7 days. With the increase in age, the 28 -day resilience modulus is $70.6 \%$ higher than the 7-day modulus, reaching 447MPa. According to the Specification of Asphalt Pavement Design for Highway, it is suggested that the resilience modulus of the 180-day stabilized soils with lime mix proportion of $8 \%-12 \%$ should fall between $400 \mathrm{MPa}$ and $700 \mathrm{MPa}$. However, the resilience modulus of the 28-day BS-100 stabilized soils is $447 \mathrm{MPa}$, more than the minimum valuespecification required. It is certain that the resilience modulus will keep increasing with the increase in age until it remains constant.

2.6 The freezing and thawing resistance

Table[6] presents that the compressive strength of stabilized soils is gradually declining with the increase in freeze-thaw cycles. By observing the specimens, it is found that most specimens are complete although they go through 5 freeze-thaw cycles. Only several specimens get some inconspicuous transverse cracks. During the second time moisture-laden experiment, it is rare to find that the exteriors and edges of the specimens begin to peel. The average compressive strength of those specimens is $1.99 \mathrm{MPa}$, with loss strength of $11.16 \%$ and a freeze-thaw coefficient of $88.83 \%$,which demonstrates a good effect of freezing and thawing resistance. 
Table 6 The data of freeze-thaw cycle experiment

\begin{tabular}{ccccc}
\hline mix proportion $(\%)$ & cycle times & compare strength(MPa) & test strength(MPa) & loss strength(\%) \\
\hline $5 \%$ lime $+0.25 \% \mathrm{BS}-100$ & 5 & 2.24 & 1.99 & 11.16 \\
\hline
\end{tabular}

\subsection{The water stability}

Table[7] shows the compressive strength development with water stability. The 1-day unconfined compressive strength of moisture-laden stabilized soils is $1.55 \mathrm{MPa}$. The loss of strength is $26.54 \%$, and the water stability coefficient is $73.46 \%$; the 3-day unconfined compressive strength of moisture-laden stabilized soils is $1.46 \mathrm{MPa}$,reducing by $0.09 \mathrm{MPa}$ compared to the 1-day strength. Referring to the control group specimens, it is found that the second group specimens have a loss of strength of $30.81 \%$. The water stability coefficient is $69.19 \%$. The loss of strength gradually increases with the increase in the soak time. Meanwhile, the 7-day unconfined compressive strength of moisture-laden stabilized soils is $1.59 \mathrm{MPa}, 0.04 \mathrm{MPa}$ higher and $0.13 \mathrm{MPa}$ higher than the 1-day strength and the 3-day strength respectively. Its loss of strength is $24.64 \%$. It can be seen that the water stability coefficient of BS-100 stabilized soils increases to $75.36 \%$. Figure 3 demonstrates a comparison of the strength of BS-100 stabilized soils in terms of different water stability.

Table7 The data of water stability

\begin{tabular}{ccccc}
\hline mix proportion $(\%)$ & soaking age $(\mathrm{d})$ & compare strength(MPa) & test strength(MPa) & loss strength(\%) \\
\hline \multirow{2}{*}{ 5\%lime } & 1 & 2.11 & 1.55 & 26.54 \\
$+0.25 \%$ BS-100 & 3 & 2.11 & 1.46 & 30.81 \\
& 7 & 2.11 & 1.59 & 24.64 \\
\hline
\end{tabular}

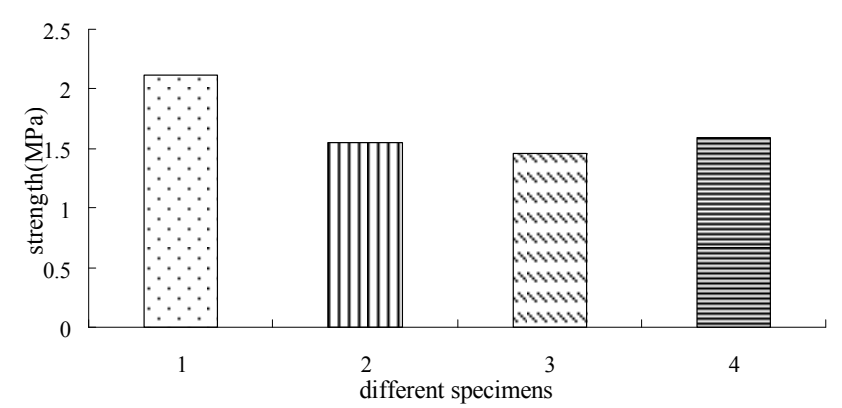

Fig.3 The strength contrast of water stability

Table 8 The data of penetration-resistance

\begin{tabular}{cccc}
\hline \multicolumn{2}{c}{ mix proportion(\%) } & \multicolumn{2}{c}{ permeability coefficient $(\mathrm{m} / \mathrm{d})$} \\
\hline lime & BS-100 & $7 \mathrm{~d}$ & $28 \mathrm{~d}$ \\
5 & 0.25 & $3.76 \times 10^{-6}$ & $2.83 \times 10^{-6}$ \\
\hline
\end{tabular}

\subsection{The penetration-resistance}

According to the Technique Specification for Seepage Prevention Engineering on Canal, the penetration-resistant of earth materials (plain earth, lime, sand and stones) should be between $8.1 \times 10^{-5}$ and $1.9 \times 10^{-4} \mathrm{~m} / \mathrm{d}$. Table[8] shows that both permeability coefficients of the 7-day and 28-day BS-100 stabilized soils reached $10^{-6}$. The permeability coefficient of the 7-day soils is $3.76 \times 10^{-6} \mathrm{~m} / \mathrm{d}$, while that of the 28 -day soils is $2.83 \times 10^{-6} \mathrm{~m} / \mathrm{d}$ which is $24.73 \%$ lower than that of the 7-day soils. Comparing with the suggested coefficient with the data we got from the experiment, we may find that the permeability coefficient of BS-100 stabilized soils is relatively lower. 


\section{Conclusion}

On the basis of the test results, the following conclusions can be drawn:

1)The BS-100 stabilized soil has a high strength in the early period and its strength increases rapidly in the later period. This property helps shorten the stage of construction.

2)The BS-100 stabilized soil has a high splitting strength. With a high splitting strength, it can reduce the possibility of the occurrence of the cracks in the base course effectively.

3)The BS-100 stabilized soil has a remarkable effect on the increase of modulus of resilience. It can greatly enhance the load-bearing capacity of pavement structure.

4)The BS-100 stabilized soil has a remarkable frost resistant effect and better temperature stability. This is significant for the construction in seasonally frozen regions.

5)With the increase in soak time, the water stability coefficient is decreasing much slower and the loss of strength is reducing and finally keeps constant. When the loss of strength reaches the lowest peak, the unconfined compressive strength increases with curing period. However, due to moisture erosion, the strength increases much more slowly. Besides, there is also a better water stability without the occurrence of secondary muddiness.

6)Because of the limitation of curing period, only the 7-day and 28-day curing data of the relationship between permeability and age are obtained. Further tests and research should be done concerning the developing tendency of its permeability with the increase in age. However, the permeability coefficient will decrease with the increase of strength in the following period.

The results demonstrate the BS-100 stabilized soils have better impermeability and freeze-thaw resistance effects, which helps to prevent settlement, frost boil and other damages in seasonally frozen regions. The BS-100 stabilizer can be applied in road projects in Changchun and other areas with similar climate and soil properties.

\section{References}

[1]Bahar, R. (2004). "Performance of compacted cement-stabilized soil." Cement \&Concrete Composites J., 26: 811-820

[2]Bo, P.(2001). "Research on liquid stabilizer reinforced soil." Journal of Xi'anHighway University J., 21(1): 15-18.

[3]Da-yan, W.(2005). "Physico-mechanical properties changes of Qinghai-Tibet clay due to cyclic freezing and thawing." Chinese Journal of Rock Mechanics and Engineering J., 24(23): 4 313-4 319.

[4]Feng-wu, L.(2003). "Application of soil solidify agent in road basic layer."Municipal Engineering Technology J., 21(5): 308-309.

[5]Jian-xiao, T. (2002). "Properties of S-soil solidified-agent for road performance."Journal of Chang'an University (Natural Science Edition) J., 22(5): 20-23.

[6]Shun-ni, L.(1998). "On the stabilizer for the soil with higher water content." Chinese Journal of Geotechnical Engineering J., 20(4): 83-86.

[7]Tong, L. (2003). "Study on indoor tests of fly ash and quick lime improving soft soils." Rock and Soil Mechanics J., 24(6): 1049-1052.

[8]Wei- rong, H.(2003). "Research on properties and application of road base materials stabilized by QJ-type soil-solidified agent." Highway J., (7): 156-159.

[9]Xiang-wei, F.(2006). "Study on engineering properties of improved soil by GT soil firming agent." Rock and Soil Mechanics J., 27(9): 1545-1548.

[10]Yi-min, W.(2006). "Pavement performances of dam embankment roads strengthened by ionic soil stabilizer." Journal of South China University of Technology(Natural Science Edition) J., 34(9): $56-61$.

[11]Yi-ning, D.(2002). "Experimental study on strengthened soft clay with stabilizer ZDYT-2." China Civil Engineering Journal J., 35(3): 82-86. 